\title{
Visual damage following direct sighting of solar eclipse in Ghana
}

\author{
Seth Lartey and Geoffrey K. Amedofu* \\ Department of Eye, Ear, Nose and Throat, School of Medical Sciences, Kwame Nkrumah University of Science \\ and Technology, KUMASI, GHANA, WEST AFRICA
}

*Author for Correspondence. E-mail: amedofugk@yahoo.com

\begin{abstract}
SUMMARY
A study was carried out at the department of Ophthalmology and Otorhinolaryngology at the Komfo Anokye Teaching Hospital/School of Medical Sciences, at Kumasi Ghana from March $29^{\text {th }}$ to May $29^{\text {th }} 2006$ to study visual acuity changes in patients suspected of solar eclipse retinopathy after they viewed an eclipse of the sun on $29^{\text {th }}$ March 2006 . In all, seven patients with eye complaints were seen. Examination included assessment of Visual Acuity (VA), Slit Lamp examination, Fundoscopy, Amsle Test, Intra-ocular pressure evaluation and Goldman's Tonometre Test. Six patients had normal visual acuity while only one had VA of $6 / 24$ in both eyes, which was corrected. All patients had normal colour vision and normal Amlser grid. None of them had any evidence of Maculopathy. 3 patients had superficial punctuate Keratitis. The absence of solar burns of the macular observed in the region is indicative of the effectiveness of mass public education concerning the damaging effects of the solar eclipse. Advanced techniques, such as scanning laser Ophthalmoscopy and the multifocal electroretinography (ERG) offer the possibility of detailed examination of small retina lesions in Ghana after an eclipse of the sun.
\end{abstract}

[Afr J Health Sci. 2007; 14:160-163]

\section{Introduction}

Visual damage following direct sighting of the solar eclipse is a well-established clinical entity of macular damage. Accounts of solar damage to the eye existed for centuries. After observing burns of the retina caused by watching an eclipse, Socrates warned against the danger of viewing the sun during an eclipse and suggested instead viewing its reflection in water [1]. Galileo reportedly was injured by using a telescope for solar eclipse observation [2]. In many societies where there are sun worshippers, eye injury is a well-documented phenomenon recognised after ritual sun observation [3]. The term eclipse retinopathy is frequently employed when the condition is sustained as a result of view a solar eclipse. The vast majority of solar retina injuries occur as a result of viewing a solar eclipse without adequate protection. The extent of structural retinal damage and associated visual impairment is dependent upon the intensity and duration of solar exposure. The exact mechanisms, which operate to produce solar retinal compromise, are not completely known, but are believed to involve a thermally enhanced photochemical process [4].

The spectrum of the light source is an important factor in retinal injury and the wavelengths in the near-Ultra-Violet- UV (320 to 400nm) and short wavelength (400 to $500 \mathrm{~nm})$ light ranges are primarily responsible for the phototoxic lesion $[4,5]$. Clinically, the lesion usually is not detected until 24 to 48 hours after the initial exposure and this includes central scotoma, metamorphopsia and photokeratitis. Severe loss occurs after $1-2$ days and visual acuity may be reduced to $6 / 60$ but has been noted to return to $6 / 12$ or better within 4 to 6 months. Since a natural phenomenon such as solar eclipse is predictable, public education is the only preventive measure [6].

On $29^{\text {th }}$ March 2006, an eclipse of the sun by the moon occurred in parts of Ghana. In Ashanti region in central Ghana with a population of 3 million people the eclipse of the sun was experienced. The city of Kumasi in the Ashanti region and the surrounding areas fall within the penumbra zone, and in this zone it is dangerous to view the eclipse throughout the eclipse phenomenon. In the days prior to the eclipse of the sun, an extensive public education was done on the television and on the local radio stations on the appropriate method of observing the eclipse of the sun and where to go for help in case of eye injury after viewing the eclipse. The incident itself was broadcast live on major television stations in the country showing eclipse watchers wearing their protective glasses. There is enough data on solar retinopathy in developed and few developing countries $[6,7,8,9,10,11]$. An eclipse of the sun has occurred in Ghana in early 1930s, but there is 
no data currently available on the effects of the phenomenon on the visual acuity of Ghanaians. There was need to conduct such an investigation to determine the magnitude of solar burns in patients reporting at the Komfo Anokye Teaching Hospital following the solar eclipse. Another rationale for the study was to determine the impact of mass public education programme on protecting the public from solar eclipse burns of the retina.

\section{Materials and Methods}

This is a 2-month active observational, noncomparative prospective case ascertainment study and it was carried out from March $29^{\text {th }} 2006$ to $29^{\text {th }}$ May 2006 following the eclipse of the sun by the moon on March $29^{\text {th }} 2006$. The study was carried out at the eye clinic at the Komfo Anokye Teaching Hospital in Kumasi in Central Ghana.

The study population includes patients reporting to the eye clinic at Komfo Anokye Teaching Hospital and who complained of eye pains and tearing sensation of one or both eyes one week after the eclipse. Exclusion criteria include known previous ocular pathology condition in the affected eye and any ocular condition found at the time of evaluation, known to present with an acute or sub-acute loss of vision. Ethical clearance was sought from the ethical committee of the school of medical sciences and the hospital. Patient consent was sought by means of written consent. In the case of illiterate patients a volunteer or a relative translated the consent form to them and they gave their consent by thumb printing.

\section{Procedure}

Announcements were made on five leading radio stations in Kumasi, the capital city of Ashanti prior to the eclipse that a special desk would be set up at the Eye Clinic at KATH to cater for all those who had eye problems related to watching the eclipse. In the clinic, patients were searched for by means of announcement at point of issuing the out-patient (OPD) cards and at the point of initial screening by an ophthalmic nurse. A total of only seven patients (3 males, 4 females) met the criteria of inclusion in the study. Their ages ranged between 13 and 50 years. The demographic and clinical features were evaluated. A detailed case history was taken including name, age, address, and a questionnaire enquiring about where the eclipse was viewed, whether protective glasses was used, the type used and how and where the patient heard about the eclipse etc. All patients had general ophthalmic examination with emphasis on visual acuity, visual field, Ishihara test, Amsler test, pen torch examination, tonometre and Funduscopy and slit lamp examination

\section{Results}

It was found that out of the seven patients seen, one heard about the eclipse in school, another one on television, two on radio and the remaining three on both radio and television (Table 1). A cursory look at the table showed that all the patients viewed the eclipse at Kumasi, six of them used solar glasses while one used a piece of cloth. Table 2 displays the status of the eyes of the patients. As can be seen, the visual acuity test indicates that 3 of the patients had a visual acuity of $6 / 5$ bilaterally, another 3 had a vision of $6 / 6$ in both eyes and one patient had a visual acuity of $6 / 24$ (refractive error) in both eyes. This was corrected. It was not due to the eclipse of the sun. We also see that all the patients had normal colour vision with the Ishinara Chart. Amlser grid was normal for all patients and there was no Maculopathy for all patients. Table 3 depicts the status of the Cornea, Intra-ocular pressure and visual fields. It can be observed that 3 of the patients had superficial punctuate Keratitis. All patients had normal Intra-ocular pressure and normal visual fields. Table 4 shows the major complaints of the patients. We do note that one outpatient had pain in the left eye, 4 had pain in both eyes, one had tearing in both eyes and another one had tearing and pain in both eyes. Observe that these complaints in all lasted for a week or less.

Table 1: Age, sex, how eclipse was heard, where and how viewed.

\begin{tabular}{|l|l|l|l|l|}
\hline PATIENT & AGE & SEX & HOW ECLIPSE HEARD & HOW VIEWED \\
\hline 1 & 31 & M & TV/Radio & Solar Glasses \\
\hline 2 & 50 & M & TV/Radio & Solar Glasses \\
\hline 3 & 13 & F & School & Solar Glasses \\
\hline 4 & 30 & F & TV & Solar Glasses \\
\hline 5 & 32 & F & Radio & Used Cloth \\
\hline 6 & 28 & F & Radio & Solar Glasses \\
\hline 7 & 44 & M & TV/Radio & Solar Glasses \\
\hline
\end{tabular}

Table 2: Status of the eye of patients. 


\begin{tabular}{|c|c|c|c|c|}
\hline PATIENT & VISION & CORRECTED & AMSLER GRID & MACULOPATHY \\
\hline & RT $\quad$ LT & VISION & & \\
\hline 1 & $6 / 5$ & & NORMAL & NIL \\
\hline 2 & $6 / 6$ & & NORMAL & NIL \\
\hline 3 & $6 / 6$ & & NORMAL & NIL \\
\hline 4 & $6 / 5$ & & NORMAL & NIL \\
\hline 5 & $6 / 6$ & & NORMAL & NIL \\
\hline 6 & $\begin{array}{ll}6 / 24 & 6 / 24 \\
\end{array}$ & $6 / 5$ & NORMAL & NIL \\
\hline 7 & $6 / 6 \quad 6 / 6$ & & NORMAL & NIL \\
\hline
\end{tabular}

Table 3: Status of the cornea, intra-ocular pressure and visual fields.

\begin{tabular}{|l|l|ll|l|}
\hline PATIENT & SLIT LAMP & IOP $\mathbf{~ m m ~ H g}$ & LT & NORMAL \\
\hline & NAD & RT & 14 & 14 \\
\hline 1 & SPK & 12 & 12 & NORMAL \\
\hline 2 & SPK & 14 & 16 & NORMAL \\
\hline 3 & NAD & 15 & 14 & NORMAL \\
\hline 4 & SPK & 14 & 16 & NORMAL \\
\hline 5 & NAD & 20 & 18 & NORMAL \\
\hline 6 & NAD & 18 & 18 & NORMAL \\
\hline 7 & \multicolumn{2}{|c|}{ NAD } & & \\
\hline
\end{tabular}

Table 4: Major complains of patients

\begin{tabular}{|l|l|l|}
\hline PATIENT & COMPLAINTS & DURATION \\
\hline 1 & Pains left eye & 1 week \\
\hline 2 & Tearing both eyes & 4 days \\
\hline 3 & Pains both eyes & 1 day \\
\hline 4 & Pains, tearing both eyes & 4 days \\
\hline 5 & Pains both eyes & 3 days \\
\hline 6 & Pains both eyes & 1 week \\
\hline 7 & Pains both eyes & 1 week \\
\hline
\end{tabular}

\section{Discussion}

The study was done to determine the magnitude of solar burns in patients reporting to Komfo Anokye Teaching Hospital following the solar eclipse and also to ascertain the impact of mass public education programme on people who viewed the eclipse of the sun without protection. Our data has shown that there were no confirmed cases of solar burns reporting and observed, two months after the occurrence of the solar eclipse of the sun in Ashanti region of Ghana with an estimated population of over 3 million people. This was in spite of the tremendous efforts in looking for these cases and the extensive public announcements that those who had solar related eye complaint should report to the eye clinic for check up. This finding of no recorded cases of permanent visual loss corroborates the previous evidence that visual morbidity following solar eclipse is likely to be temporary [6]. Indeed, during the solar eclipse in the United Kingdom in 1999 , only 14 cases of retinopathy were recorded one week after the eclipse and no confirmed cases were reported in any of the specialist clinics serving Scotland, Wales and Northern Ireland. It is known that most of the known cases in this report watched the sun without protecting the eyes.

This finding of minimum occurrence of retinopathy following the eclipse is however at variance with other reports $[12,13]$. Kallmar and Ygge [12] followed 15 patients all of whom viewed the solar eclipse in Sweden for one year and reported that Photo induced foveae injury gave rise to subjective visual disturbances, reduced VA and morphological changes in the fovea. Central Scotomas could still be seen in all patients one year after their foveal injury when scanning laser ophthalmoscopy was used. Similar finding was reported in the Strasbourg study when the multifocal electroretinogram (ERG) was used on 4 patients after the $11^{\text {th }}$ August 1999 eclipse of the sun. The use of scanning ophthalmoscopy and multifocal electroretinogram offer the best possibility of detailed examination of small retinal lesions and foveolar deficit [12, 13] which can sometimes be difficult to localise with ophthalmoscopy. Additionally, Mack and Flament [13] assert that the multifocal ERG has yet to be equalled by any test for analysis of macular lesion. We did not use these techniques in our evaluation of patients, because we do not have the facility. Only 3 cases of superficial punctuate Keratopathy 
were recorded. This may either be related to the solar eclipse or coincidental since on average $5-10$ cases of superficial punctuate Keratitis are seen daily in the eye clinic through out.

The limited number of patients reporting for check up after the solar eclipse and the absence of solar burns of the macular observed in the region is suggestive of the importance of radio and television in educating the public on the effects of solar eclipse. Thus it would appear that the media is a good tool of informing the public about health matters.

\section{Conclusion}

Solar retinopathy is a well-recognised clinical entity of macular damage by viewing the sun. In Ghana considerable public excitement was raised in anticipation of the eclipse of the sun on $29^{\text {th }}$ March 2006. Cases of solar retinitis, which can even lead to permanent loss of vision, have been reported in the international literature. To forestall any eye problem which could result from viewing the eclipse of the sun without proper protection, the eye unit at Komfo Anokye Teaching Hospital undertook an extensive mass public education on the proper way to view the phenomena.

After the eclipse, only seven people reported to the hospital with symptoms they attributed to the eclipse, and out of this no solar Maculopathy was observed. There were only three cases of superficial punctuate keratopathy which may or may not be due to the eclipse. It would appear that cases of retinopathy might be observed if current techniques such as multifocal ERG and scanning laser ophthalmoscopy were used. Deducing from the low turn out of people to the clinic after the incidence, we could assert that the mass public education was most effective in reducing visual morbidity.

Lasting visual damage can follow a solar retinal burn with little or no form of viewing devices. While it is reasonable to surmise that some patients may ignore their visual complaints and not report to the hospital, we can conclude that prevention remains the best treatment and there is a need to educate the public in this regard not only against the damages of retinopathy but also other negative health hazards such as uptake cataract, surgical services and HIV.

\section{References}

1. Guerry RK, Ham WT and Mueller HA. Light toxicity in the posterior segment. In: Duane TD and Jaeger EA (eds) Duanes Clinical Ophthalmology. Philadelphia, Harper and Row. 1986; 3: 1- 17.

2. Sliney DH and Wolbarhst ML. Safety with lasers and other Optical sources. New York, Plenum Publishing 1980. 1064 p
3. Yannuzza LA, Fisher YL, Krueger A et al. Solar Retinography: A photobiological and geophysical analysis. Transactions of American Ophthalmology Society. 1987; 120: $1-20$.

4. Stock TH. Solar retinopathy: a review of literature and case report. Journal of American Ophthalmology Association. 1985; 56: 374-382.

5. Ham WT, Mueller HA, Ruffolo JJ, Millen JE, Jeary SF, Guerry RK, Guerry D3rd. Basic mechanism underlying the production of photochemical lesions in the mammalian retina. Current Eye Research. 1984; 3: 165-174.

6. Michaelides M, Rajendram R, Marshall J, Keightley S. Eclipse retinopathy. Eye 2001; 15: 148-151.

7. Mwanza JC, Kayembe DL, Kaimbo DK, Kabasele PM, Ngoy DK. Solar retinopathy acquired after gazing at the sun during prayers. Bulletin de la Societe Belge d'Ophthalmologie. 2000; 275: 4145.

8. Rai N, Thualadar L, Brandt F, Arden GB, Berninger TA. Solar retinopathy: A study from Nepal and from Germany. Documenta Ophthalmologica. 1998; 95: 99-108.

9. Kawa P, Mankowska A, Mackiewicz J Zagorski Z. Solar retinopathy. Klinika Oczna.1998; 100: 235-237.

10. Verma L, Sharma N, Tewari HK, Gupta S. Retinopathy after solar eclipse, 1995. National Medical Journal of India. 1996; 9:266-267.

11. Juan-Lopez M and Pena-Corona MP. A strategy for preventing health injuries due to observing the solar eclipse in Mexico. Salud Publica de Mexico. 1993; 35: 494499.

12. Kallmark FP and Ygge J. Photo-Induced foveal injury after viewing a solar eclipse. Acta Opthalmologica Scandinavica. 2005; 83: 586-589. 